\title{
Research paradigms and the tourism curriculum
}

\author{
Author: $\quad$ Dr. John Tribe \\ Faculty of Leisure and Tourism \\ Buckinghamshire Chilterns University College \\ High Wycombe, Bucks, HP11 2JZ, UK \\ tel: 01494605163 \\ fax: 01494448601 \\ email: john.tribe@bcuc.ac.uk
}

John Tribe is Principal Lecturer in the Faculty of Leisure and Tourism at Buckinghamshire Chilterns University College (High Wycombe, Bucks. HP11 2JZ, UK. Email john.tribe@bcuc.ac.uk), and visiting lecturer at the University of Surrey. His current research interests include tourism higher education, tourism in developing countries and environmental management systems in tourism. 


\begin{abstract}
A critique of tourism curriculum proposals in the literature enables different methodological approaches to curriculum design to be surfaced and evaluated. Three methodological paradigms for researching into the curriculum emerge. These are the scientific positivist, the interpretive and the critical.
\end{abstract}

The analysis of this paper points up differences between research paradigms, the implications of using each of them for curriculum design, and the limitations of scientific positivist approaches. It finds that methods which are exclusively scientific positivist may have only limited application because of their lack of attention to meaning and values and underlines the importance of approaching curriculum design mindful of the full range of research paradigms. 


\section{Introduction}

This paper classifies and evaluates methodologies used to design the tourism curriculum. It does this by way of a critique of recent proposals for the curriculum in the literature of tourism higher education. These are the Koh (1995) study and the National Liaison Group for Higher Education in Tourism (NLG) proposals (Holloway, 1995). Koh's marketing approach was to survey industrialists and academics as a basis for design of the tourism curriculum and the more recent World Tourism Organisation / Bournemouth University study (Shepherd, 1997) deploys a similar method. The NLG approach has been to generate its core curriculum from a committee of NLG members and debate the issue at a national conference which took place in December 1994.

The critique of these proposals enables different methodological approaches to curriculum design to be surfaced and evaluated. Three methodological paradigms for researching into the curriculum emerge. These are the scientific positivist, the interpretive and the critical.

The analysis of this paper points up differences between research paradigms, the implications of using each of them for curriculum design, and the limitations of scientific positivist approaches. It finds that methods which are exclusively scientific positivist may have only limited application because of their lack of attention to meaning and values and underlines the importance of approaching curriculum design mindful of the uses of different research paradigms. This is particularly important in 
view of the rapid global growth of tourism and the sustainability issues that are generated by this growth.

\section{Research paradigms and the tourism curriculum}

\section{Method, methodology and research paradigms}

Before engaging directly with these proposals, it is important to draw a distinction between method and methodology in curriculum design. Method is a particular way or developed routine for approaching a research question. It can be classed as a technique. In some cases a particular method is clearly suggested by the question itself. For example, the hypothesis that tourism undergraduates are less well qualified at entry into higher education than other undergraduates would suggest an empirical method and the use of a survey as the technique for testing the hypothesis.

Methodology on the other hand is explained by Cohen and Manion (1994, quoting Kaplan) as a means:

\footnotetext{
"to describe and analyse these methods, throwing light on their limitations and resources, clarifying their presuppositions and consequences, relating their potentialities to the twilight zone at the frontiers of knowledge." (1994:39)
}

Now it seems that there is considerable confusion between methodology as perceived by Kaplan and its common usage. For in the case cited above, the use of survey method to test a hypothesis, methodology is often taken just to mean a detailed 
exposition of the rudiments of a particular method. In the example about undergraduate entry qualifications the focus would be on the procedures to be adopted to ensure that the survey method resulted in a valid conclusion. Thus "methodological" issues would include those of sampling, of sampling error, of questionnaire design and of statistical presentation and interpretation of results. "Methodology", in this usage is the process for ensuring a particular technique has scientific validity.

Methodology is frequently used in the same way in tourism education research. For example Koh (1995:69) has a section titled "research methodology" which describes the detail of a particular method - a two-phased survey, sample size and sampling techniques - which were used to inform the design of a tourism curriculum. But Kaplan is implying an altogether different meaning of methodology. He is arguing that it means not just a detailed exposition of the specific method to be used, but a sustained reflection on methods in general. In this view, methodology is more a matter of considering the nature of the research question being posed and considering, from a range of possible methods, which might be an appropriate approach or combination of approaches. This implies that the researcher has some breadth of knowledge about the extent of possible methods and can survey the landscape of methods from a vantage point with an overview. It also implies that the whole process of research is opened up to critical reflection. It is what Hammersley (1992) and Usher (1996) call reflexivity in research.

The significance of adopting a methodological approach is to be aware of possible problems of partiality and premature closure. As Usher explains: 
"I may think for example my research is simply a

neutral 'finding out', but the kinds of questions I ask and the methods I use may mean it functions oppressively." $(1996: 37)$

One problem then, is that the conclusions offered to some research questions may be determined more by the method deployed than the data being studied. In other words different methods would generate different outcomes. Take the following research question - "What modules should constitute a tourism degree?". A methodological trap is present here. If the researcher moves too quickly to a quantitative survey method, the bulk of the research effort is committed to the statistical techniques of sampling, questionnaire design and so on, as in the earlier example about entry qualifications. But a vital difference between the two examples is that the question of meaning of tourism education in the second example is much less clear than that of degree entry qualifications in the first. Hence the importance of initial methodological deliberation in the Kaplan sense.

Proper attention to methodology rather than a rush to a preferred method will mean that the problem of the meaning of tourism education is addressed. This may entail a conceptual enquiry to be engaged in prior to, or in conjunction with, subsequent work which itself may comprise ethnomethodological, interview or survey techniques. It is possible that the results of such an approach would be completely different to a "straightforward" survey since each approach would be measuring a differently defined education. In one case, education is pre-defined by the researcher, whilst in the other case education is interpreted through a more open dialogue with its 
stakeholders who are transformed from objects to subjects of the research. Hence the earlier assertion that research solutions may be determined by method. Usher paraphrases Gadamer's caution that:

"Understanding an object is always 'prejudiced' in the sense that it can only be approached through an initial projection of meaning." (1996:21)

Conscious of the propensity of method to determine results, (i.e. to endorse one version of the truth in a situation of multi- truths), a methodological enquiry follows. The Koh and NLG proposals are situated in competing research paradigms, and the implications of approaching curriculum design from within different paradigms is analyzed.

Usher explains a research paradigm as:

"an exemplar or exemplary way of working that functions as a model for what and how to do research, what problems to focus on and work on." (1996:13)

The point about paradigms is that there can be more than one of them, that they offer distinctively different ways of doing things and that they direct methods and practices. In research into the tourism curriculum, as in other areas of social sciences, there are paradigms based on scientific positivism and those based on alternative approaches. 


\section{The scientific positivist paradigm}

There are several defining characteristics of scientific positivist research. First, it concentrates on positive data - that is on facts that can be verifiable and can survive attempts at falsification. This essentially excludes questions of a moral or ethical nature which cannot be settled by an appeal to facts. The world of ought is therefore ruled out of bounds in favor of the world of is. Next rigorous scientific method is used, based upon hypothesis formulation, and testing against empirical evidence. Quantitative measurement and experiment are key techniques here. Researchers adhere to the principle of value neutrality. In effect their role becomes one of a specialist conduit giving access to facts. They are in theory replaceable by any other researcher who would reach identical results using the same data and methods.

The NLG and Koh set out to find the key elements of the core curriculum by an appeal to the facts using the scientific-positivist paradigm. The NLG aim was to seek "some consensus on the body of knowledge which would be acceptable to both academics and practitioners in the tourism industry." (Holloway, 1995:2). This consensus was sought at a national conference attended by academics and industrialists that was held in London in December 1994. However the conference was not provided with a tabula $\underline{\text { rasa, }}$, but rather with a set of "seven 'areas of knowledge' on which the committee members of the NLG were agreed.” (Holloway, 1995:2)

Reference to an earlier review by the UK Council for National Academic Awards (CNAA, 1993: 32), enables the genealogy of the NLG project to be traced and there 
can be found seven similar subject areas. The CNAA review is more explicit on how these seven areas have been identified. They are based upon:

- Airey and Middleton's (1984) review of the curriculum of tourism courses (which was based on Burkart and Medlik's (1981) 'Body of Knowledge', and,

- “information supplied by academic institutions for this review" (CNAA, 1993:32)

We may therefore note in the NLG proposals a strong link with an scientific-positivist methodology. Koh's study is explicitly scientific-positivist. Its rationale being that hitherto there had been "little or no empirical input from industry" (Koh 1995:68) on current U.S. programmes. This is a deficiency which Koh seeks to redress by using a survey-based method.

Both the NLG and Koh approaches can be understood as operating within the model proposed by Tyler (1949) in which four major curriculum questions are posed:

1. What educational purposes should the institution seek to attain?

2. What learning experiences should be selected?

3. How should these learning experiences be organized?

4. How can the effectiveness of learning be evaluated? 
In fact it can be seen that the NLG and Koh only really address the second of these questions and that the answer to the first question is implicit in their answer to the second. That is that the educational purposes presupposed by the NLG and Koh are those serving the interests of the business of tourism.

It is here that the notion of value neutrality for scientific positivism is demonstrated to be an incomplete one. Data collection methods deployed by Koh were undoubtedly value free. But an initial value position is imposed by seeking empirical input from industry. The value imposed is that of industry values. Pinar and Grumet (1981) criticise the Tyler-type approaches to curriculum design, noting “its more recent mirroring of scientific (mainstream social) method and its apolitical and ideological function." (1981:30)

This is a criticism that might fairly be levelled at Koh and the NLG since they approach curriculum design in a similar style to that of Tyler. Their implicit adherence to business values with little regard to the possibility of competing values suggests that they are unconscious of the ideological positioning of their studies.

This is a clear case of method imposing closure on the result. Since the research question has defined the key data to be collected as the opinions of tourism managers, the results are a tourism curriculum for the efficient management of tourism with an emphasis on operational expertise such as financial control and marketing. Now this should produce graduates who are good managers, innovative and are customercentric. But the closure imposed is an emphasis on means and technique at the 
expense of purposes. Ends are givens and are rarely subject to critical scrutiny. Purpose is assumed to be coterminous with profitability.

The consequences of such curriculum orientation is to produce managers who demonstrate not so much a lack of concern to the social consequences of the singleminded pursuit of business efficiency but rather who are largely blind to such consequences. For social consequences are not part of the agenda of a tourism curriculum designed by positivist methodology. Ironically, scientific positivism's pursuit of value freedom has in this case endorsed a value position of business values.

Another difficulty is the belief that the use of scientific positivist method will of itself solve the questions of curriculum design. This is particularly apparent in the methodological (ic) underpinnings to Koh's work. Here the combination of survey and Delphi technique are proffered to produce what is seen as an objective solution to the problem. It is implied that the results of such a method are the solution. Indeed Koh states that a cross-sectoral sample of tourism industry executives would "validate" the findings (Koh, 1995:68). But the Koh technique is to bring in a particular theory to solve a problem rather than to generate a theory which is shaped by the practical reality of the situation. Koh's findings are in fact partially predetermined by the use of the parameters of his survey technique. The method determines the result. The results are only valid for those who were asked. Thus Koh's claim for validity is a limited one.

Next, scientific-positivist method objectifies the researched world. It ascribes a reality to this world according to the purposes of the research. It includes and excludes 
factors and defines its terms with regard to solving the 'problem' to be resolved. The reality of the researched world is not admitted as a problem in itself.

What all this adds up to is a method that produces a vocationalist curriculum based on technique and means rather than on consideration of ends. The production of graduates with good business technique is of course a key aim of tourism higher education, particularly for students who have enrolled for a vocational degree. Thus scientific positivist methods have an important place in the development of the tourism curriculum. In this respect, both the NLG and Koh proposals are to be welcomed as contributing clarification to the classification of essential components of the curriculum in order to meet the requirements of technical skill.

However what is questionable is whether it is appropriate to allow such methods to dominate the design of the tourism curriculum. Such an approach - the elevation of scientific positivism to the paradigm for curriculum thinking - can lead to a one dimensional (Marcuse, 1968) development of the curriculum.

In this one dimension, a critical view of society is missed. Bourdieu's (1990) thesis of cultural and social reproduction and a self-legitimating system suggests a problem here. An uncritical curriculum, implicitly endorsing the dominant business ideology, can play a part in the reproduction of an imperfect society. It is in response to these issues that this enquiry turns next to alternative paradigms for curriculum research, which are captured under the headings of the interpretive and the critical. 


\section{Alternative paradigms}

Alternative paradigms do not necessarily supplant scientific positivism. Indeed even the sceptical Hammersley points out the importance of scientific positivism to educational researchers. He adverts particularly to its concern with: "clarity of expression" and its "systematic treatment of evidence, of searching for and taking due account of negative evidence, rather than simply fitting interpretations to selected evidence." (1992:18)

Walle offers a balanced view whilst signalling potential problems:

"Science provides a powerful methodology, however, it tends to eliminate the investigation of topics that are not easily attacked using its techniques." (1997:532)

Walle's main criticism is that scientific positivism's rigorous method can lead to an oversimplification of reality. This results from the exclusion of phenomena which cannot be processed by its methods. The rich complexity of the world as lived is sidestepped.

Alternative methodologies allow some of the limiting assumptions and requirements of scientific positivism to be waived. Positivism's requirement to deal in verifiable facts is lifted. This allows opinions to be voiced and the admittance of data, and areas of enquiry that are excluded from positivism by the verifiability principle. Walle 
explains for example that emic methods allow "attitudes, motives, interests, responses, conflict and personality" (1997:529) into research.

In alternative paradigms, the idea of a single objective reality which exists independently of the researcher is replaced by a more fuzzy world of multiple realities. The significance of subjectivity in forming these multiple realities is recognized. The idea of value neutrality comes under closer examination as ideology and "taken for granteds" are held up for scrutiny. Indeed values, ends and ethics are often welcomed into the discussion, in contrast to positivism which "abandons ethics and politics to irrationalism" (Hammersley, 1992:18, paraphrasing Habermas). In alternative paradigms the human aspect of research activity is realized and interactions between the researcher and the researched world are foregrounded. At the extreme, the research process becomes more like an art than a science.

These characteristics are found in varying degrees in the main alternative research paradigms of the interpretive and the critical.

\section{The interpretive paradigm}

The interpretive approach to curriculum design seeks understanding and meaning. So whilst in the scientific positivist tradition the social world is objectified by the researching subject, the interpretive tradition treats the social world as subject, encouraging it to speak for itself. For example, in the scientific positivist tradition students and tourist hosts become objectified, the former objects of a curriculum and the latter objects of tourism. 
The interpretive approach holds that human actions and social constructs (such as the curriculum) cannot be treated by researchers in the same way as natural objects. Within the interpretive paradigm insight into the tourism curriculum is sought by reference to the participants in the curriculum in the widest sense. It is they who provide the starting point. This is in contrast to the scientific positivist approach where, typically, a hypothesis is formulated using meanings which have been ascribed from the researcher's preconceptions. This hypothesis is then subject to empirical scrutiny and the method, which appears to be value-free, clouds the values impregnated in the whole exercise. In the scientific positivist approach the social world is frozen into an objectified reality. It can only speak through the limited aperture provided by the research instrument.

Grundy explains that for a curriculum designed by interpretive methods:

"all participants in the curriculum event are to be regarded as subjects, not objects.” (1987:69)

By this Grundy means that the curriculum researchers should not set themselves up as subject and then objectify other possible participants in the curriculum event, so that they become mere actors in her or his script. Rather, the possible participants in the curriculum event should be cast as subjects and be invested with the power of authorship. The script, in this case the tourism curriculum, is therefore written with a more open mind and more collaboratively.

So the interpretive method for designing a tourism curriculum aims to promote understanding of tourism from the point of view of all the stakeholders in the tourism 
environment. The extent of the tourism world, and tourism aims and purposes are not pre-determined or pre-defined. Rather, part of the interpretive method is to seek agreement and understanding of the tourism world and tourism purposes.

What this means is that the tourism world is not just a narrow business world where the key social actors are the tourist and the tourism providers. Rather other stakeholders are given much greater voice in the interpretive method, whether positively engaged in the business of tourism or not. An interpretive method for curriculum research would therefore encourage accounts from all the actors affected by its operation. Students, tourists, tourism businesses, tourism employees, host communities, and others affected or interested in the tourism phenomenon will count. It will define tourism's society, that is all those with a stake in tourism, widely. It will seek a consensual interpretation for the curriculum, or accept multiple interpretations. Whilst the voices of academics and industrialists have been sought in the designs of the two curricula under examination, the voices of this wider tourism society have not been given expression. The methods deployed under the interpretive paradigm range from the more structured qualitative techniques of focus groups and participant observation, through accounts, case studies and action research, towards the more artistic methods of hermeneutics, literary criticism, and emics.

\section{The critical paradigm}

Substituting "students" for "children" in Young's observation, and inserting the term tourism gives a good idea of the concerns of critical theorists of the curriculum as applied to tourism higher education: 
"[students] must be prepared to take their place in a [tourism] society that already exists ... the [tourism] society which exists is only an imperfect representation of what it could be." (1989:2)

Such concerns signal possible curriculum shortcomings and again Young expresses these with clarity, reworking the words of Hegel:

"we are potentially a self-forming species, if only we could recognise and vitalise our capacity to be aware of our authorship of history." (1989:27)

Critical theory holds out a special promise for tourism world-making. The critical paradigm utilizes critical theory developed by the Frankfurt School (Horkheimer, Adorno, Marcuse and Habermas) which itself develops thinking from Marx and beyond. In particular, critical theory exposes the interests which are associated with different research paradigms. Habermas's theory of knowledge-constitutive interests concludes that there is no interest free knowledge. In Knowledge and Human Interests (1978) he sets out the three interests that motivate human inquiry.

***insert table 1

Critical theory suggests that a tourism curriculum derived from positivist methodology serves technical interests. In this case the interests of nature are subordinated to the interests of man (Gibson, 1986). One might adjust this view to suggest that the 
interests of mankind are subordinated to the interests of particular interest groups. A critical approach to the tourism curriculum would seek to expose and rectify this imbalance and seek emancipation from the grip of any particular ideology.

This emancipatory cognitive interest is described by Grundy as leading to a: "transformation in the way in which one perceives and
acts in 'the world'." (1987:99)

The emancipation which is sought through critical theory is a triple one. First emancipation from control by technical interests, second, emancipation from ideology and third emancipation by appropriate action to change things for the better.

Habermas's (1978) critical theory entails consideration of the purpose of knowledge and admits values, moral issues and repercussions into the frame of critical thinking. This is in contrast to scientific positivism where means and ends, facts and values and theory and practice are separated out, so that only means, facts and theory remain. In critical theory:

\footnotetext{
"knowledge and interest in emancipation coincide and thus make for those unities which positivism severs theory and practice, means and ends, thought and action, fact and value, reason and emotion.” (Gibson, 1986:37)
}

Attention is now turned to how critical theories may be applied to tourism education. 
A neo-Marxist critique of the tourism curriculum would be that the superstructure of society which includes education along with institutions such as the law and the government is determined by the base of economic and material factors. Under this 'base determines superstructure' theory, tourism education would be charged with training a workforce for the base with the necessary personalities and attitudes.

The narrow list of management of tourism type modules suggested by Koh and the NLG does illustrate the potential for base to determine superstructure. However the simple Marxist deterministic model cannot account for the considerable autonomy enjoyed by educational institutions of the superstructure and indeed their ability to turn their critical sights against the interests of the economic and material base.

The concept of ideology is more relevant to the curriculum than that of crude economic determinism. For Habermas, a key problem for scientific positivism is its failure to be sufficiently conscious of the influence of ideology on choice of research questions, methods and thus findings. He deployed ideology critique as a means of identification of ideology. This critique offers the possibility of escape from ideology. Critique enables self-understanding and reveals other possible views of the world.

An ideology is a system of beliefs that directs the policies and activities of its adherents. The job of critical theory is initially to identify which particular ideological influences are at work. Ideology critique then asks whose interests are being served by a particular ideology. The very nature of ideology can make these tasks difficult. Common sense, "taken for granted" systems can mask the existence of an ideology. 
Gramsci's (1971) concept of hegemony helps our understanding ideology in this respect.

In its original political meaning, hegemony referred to the influence of one state over another. Gramsci's development of the concept is more subtle. He uses the term not to describe the explicit, conscious imposition of one ideology on a range of unwilling groups. Instead, his use of the term refers to the situation where a collection of ideas an ideology - permeates and saturates the natural way of thinking of a society. It becomes the accepted or common sense view of the world. In other words our perception of reality is coloured by this accepted view of things which is historically rooted. The deeply embedded nature and long tradition of a particular ideology serves to camouflage its existence.

It is suggested that the underlying dominant common-sense view (ideology) which permeates most literature and research on the tourism curriculum is a vocationalist one. Its guiding idea is that tourism should be organised to bring profit to the organising company and satisfaction to the paying tourist. This is the common-sense background in which the NLG and Koh are operating. What both of their approaches lack is a consciousness or a critical scrutiny of this ideology. The ideology promotes particular kinds of knowledge as evident in the Koh and NLG curricula. They favor marketing, measurement, management and planning and whilst there are signs of questioning components (sustainability, environmental impacts) they are as adjuncts to the main thrust of the business of tourism. Neither curriculum holds up the whole tourism enterprise for deep critical evaluation. Neither asks whether the tourism world which we are creating is the tourism world we want. For, not least, the composition of 
"we" (i.e. the arbiters of the tourism world as it is developing) is assumed to be businesses and tourists with purchasing power. Employing critical theories to the curriculum would seek to develop descriptions and theories about tourism which are not dominated by the operation of a particular ideology. As Arendt expresses it:

"critical thinking makes others present and thus moves potentially in a space which is public, open to all sides." $(1978: 257)$

\section{A partial curriculum}

From the preceding analysis it can be seen that the Koh and NLG curricula utilize scientific positivist methods, and largely overlook interpretive or critical approaches. A number of points derive from this.

1. The two proposals effectively clarify the essential dimensions of a vocationalist tourism education to serve technical interests.

2. The ultimate beneficiaries of tourism degrees constructed according to such blueprints are employers and tourists, and the employed side of students. A wider tourism society is not necessarily well served.

3. Both curricula carry considerable pre-suppositions which are not made explicit.

4. Both curriculum proposals bracket values out of their approaches. 
5. Both curricula have a hidden curriculum of values, i.e. business interests are valued more highly than other interests.

6. The ideology legitimated by these proposals is that tourism is conceived of as a phenomenon which should be organised to bring profit to the organizing enterprise and satisfaction to the paying tourist.

7. Both proposals perform a legitimating function for the status quo, business and the emerging orthodox tourism curriculum.

8. Both proposals act as if there was no problematic merely a question of more or less marketing or finance.

9. There is emphasis on means at the expense of consideration of ends.

10. The tourism world is objectified according to the preconceptions of the researchers.

11. The narrow methods employed by each proposal determine a narrow curriculum.

12. Such methods tend to be reproductive of the world that is rather than consider the world that could be.

This points up the limitations of a positivist-scientific empirical approach to curriculum design. These are summarised in column 4 of table 1. A partial, rather than comprehensive curriculum has emerged. Curriculum design requires more than an 
analysis of business wants. For the consumer of the tourism curriculum is not just business, as Koh implicitly believes but it is the wider tourism society that is affected by the tourism enterprise. We need to hear these other voices.

\section{Conclusion}

A gap in curriculum research in tourism is evident from this analysis. This gap is caused by the fact that existing analyses of the curriculum operate within a research paradigm that results in only a partial account of the possible curriculum for tourism higher education. In particular, a shortcoming of this is a lack of attention to the aims and purpose of a tourism curriculum. Table 2 is used to identify the research paradigms used by the NLG and Koh curricula. Only scientific positivism was employed and the interpretive and critical paradigms were overlooked. In this respect the paradigm within which the NLG and Koh proposals operate can be characterised as necessary but incomplete. This conclusion considers how this problem may be approached.

***insert table 2

A curriculum is socially constructed, that is to say it is the product of human thought and negotiation. Curricula, as Young noted, "are no less social inventions than political parties or new towns." (1971:24). Curricula are forged by men and women and for men and women, and so curriculum analysis must take account of a complex series of interpenetrations between the conceiver, the conceived, the conceived for whom, and the conceived for what purposes. 
A curriculum for tourism needs to develop a tourism society not just as society for business but one of society for all its stakeholders. In other words practical and emancipatory interests need to be addressed as well as technical interests. This requires research to be undertaken using approaches from all three methodological paradigms using the full range of positivist, interpretive and critical methodologies. In some cases an empirical method will be appropriate, for example in attempting to match curriculum content to vocational needs. This is because vocational needs are capable of objective measurement, at least theoretically.

But to design a curriculum to include non-vocationalist aspects, questions of meaning and purpose of the curriculum arise. It is here that an emphasis on reflective philosophical method becomes necessary. Lawton (1983), writing about curriculum design for schools, proposed a curriculum planning model with two initial stages. These required philosophical and sociological analysis. Initially, Lawton holds that philosophical questions must be raised and addressed. These questions relate to the aims of education and the meaning of a worthwhile education. Sociological questions relate to the kind of society we have. It is vital in Lawton's view to resolve such questions before the next stage of curriculum design - in this case selecting modules may proceed. It is concluded that Lawton's approach be used to address the problem that has been identified. That is that an interpretive methodology (albeit with philosophical deliberation over meaning) and a critical approach underpinned by sociological analysis, are utilized prior to or at least in conjunction with, any other research. The specifics of such a curriculum will be tackled in a subsequent paper where the importance of curricula themes such as "Mindful Managers" (Moscardo 
1997), critical skills, reflective practice (Schön, 1983) and liberal reflection as well as dedicated modules such as practical philosophy for tourism will be addressed. 


\section{References}

Airey, D. and Middleton, V. (1984). "Tourism Education Course Syllabuses in the UK: A Review." Tourism Management, 5(1).

Arendt, H. (1978). The Life of the Mind. New York: Harcourt Brace and World.

Bourdieu, P. (1990). (trans. R. Nice), Reproduction in Education, Society and Culture, 2nd ed. London: Sage Publications.

Burkart, A. and S. Medlik. (1981). Tourism, Past, Present and Future. London: Heinemann.

Carr, W. and S. Kemmis. (1986). Becoming Critical. Sussex: The Falmer Press.

Cohen, L. and L. Manion. (1994). Research Methods in Education. 4th ed. London: Routledge.

Council for National Academic Awards (1993). Review of Tourism Studies Degree Courses. London: CNAA.

Gibson, R. (1986). Critical Theory and Education. Kent: Hodder and Stoughton. Gramsci, A. (1971). (trans. Q. Hoare and G. Smith), Selections from the Prison Notebooks. New York: International Publishers.

Grundy, S. (1987). Curriculum: Product or Praxis. Sussex: Falmer Press.

Habermas, J. (1978). Knowledge and Human Interests. London: Heinemann.

Hammersley, M. (1992). "Two Cheers for Positivism! or, What Can Educational Researchers Learn from the Philosophy of Science?” paper presented at, $\underline{\text { Seminar }}$ on Methodology in Educational Research.

Holloway, C. (1995). Towards a Core Curriculum for Tourism: A Discussion Paper. London: The National Liaison Group for Higher Education in Tourism. 
Koh, K. (1995). "Designing the Four-Year Tourism Management Curriculum: a Marketing Approach." Journal of Travel Research, 33: 68-72.

Lawton, D. (1983). Curriculum Studies and Educational Planning. London: Hodder and Stoughton.

Marcuse, H. (1968). One Dimensional Man. London: Sphere.

Moscardo, G., (1997). "Making Mindful Managers." Journal of Tourism Studies, 8(1): $16-24$.

Pinar, W. and M. Grumet. (1981). "Theory and Practice and the Reconceptualisation of Curriculum Studies." In M. Lawn and L. Barton (eds.), Rethinking Curriculum Studies. London: Croom Helm.

Schön, D., (1983) The Reflective Practitioner. London: Maurice Temple Smith. Shepherd, R. (1997). "The Graduate Tourism Aptitude Test (GTAT)." In E. Laws (ed.), The ATTT Tourism Education Handbook. London: The Tourism Society.

Tyler, R. (1949). Basic Principles of Curriculum and Instruction. Chicago: University of Chicago Press.

Usher, R. (1996). "A Critique of the Neglected Epistemological Assumptions of Educational Research." In D. Scott, and R. Usher (eds.), Understanding Educational Research. London: Routledge.

Walle, A. H. (1997). "Quantitative versus Qualitative Research." Annals of Tourism Research, 24(3): 524-536.

Young, M. (ed.) (1971). Knowledge and Control. London: Collier Macmillan. Young, R. (1989). A Critical Theory of Education. Hemel Hempstead: Harvester Wheatsheaf. 
Table 1 Knowledge-constitutive interests

\begin{tabular}{lllll}
\hline Paradigm & Assumptions & Interests & General & Outcomes for the tourism \\
& & & outcomes & curriculum \\
\hline Scientific & Separation of fact & Technical & Prediction and & Problem of competing values \\
positivism & and values: & & control; & ignored. Curriculum design \\
& Concentration on & & instrumental & based on measurable facts \\
& fact & action & \\
Interpretive & Difficult nature of & Practical & Enlightenment & Importance attached to \\
method & "facts" and & & and & multiple understandings of \\
& importance of & & understanding & tourism world in curriculum \\
& relativism & & & design \\
Critical & Unification of facts & Emancipatory & Liberation & Values are given due weight \\
theory & and values & & & in curriculum design. \\
& & & & Curricula less prone to
\end{tabular}


Table 2 Methodological paradigms for curriculum research

\begin{tabular}{lcc}
\hline Paradigm & NLG & Koh \\
Scientific positivism & $\checkmark$ & $\checkmark$ \\
Interpretive method & & \\
Critical theory & & \\
\hline
\end{tabular}

